\title{
Derivation and Interpretation of Expressiveness Devices in North Hail Arabic: Minimalist Account
}

\author{
Murdhy Alshamari ${ }^{1}$ \\ ${ }^{1}$ Department of English Language, College of Arts, University of Ha'il, Hail, Kingdom of Saudi Arabia \\ Correspondence: Murdhy Alshamari, Assistant Professor of Theoretical and Chomskyan Linguistics, \\ Department of English Language, College of Arts, University of Ha'il, Hail, Kingdom of Saudi Arabia. E-mail: \\ snxparticles@yahoo.com
}

Received: July 27, 2020

Accepted: August 26, $2020 \quad$ Online Published: August 30, 2020

doi:10.5539/ijel.v10n5p351

URL: https://doi.org/10.5539/ijel.v10n5p351

\begin{abstract}
This paper investigates the interpretive properties of what are termed expressiveness devices, characterised as clitic, pronoun and demonstrative. In what seems to be cases of multiple expression of a single argument, the proposed investigation involves generative syntactic analyses to the interaction of a set of expressiveness devices with an associate DP, accounting for their interpretation at both LF and PF interfaces (Chomsky, 1995 et seq). Exploration of a set of North Hail Arabic (henceforth, NHA) data containing expressiveness devices, all of which agree in $\varphi$-features with the associate DP, it is shown that the expressiveness devices maintain rigid order in the left periphery of the clause, each generated for certain discourse-interpretive property expressing a distinct value of information structure, through establishing an Agree relation (Chomsky, 2001) with the associate DP. Amongst the insights the analyses show is that NHA allows for multiple probes agreeing with a single goal. In this way, a probing head probes through another c-commanded probing head, in which case the goal is visible to the upper probing head. Movement is therefore shown to be triggered in case where goal's visibility, related to feature valuation, is not available, hence, movement presupposes agreement.
\end{abstract}

Keywords: expressiveness device, agreement, movement, left periphery, interpretation

\section{Introduction}

Pronominals, dubbed in this research 'expressiveness devices', characterised as clitic, pronoun and demonstrative, have been widely investigated in the generative literature (Shlonsky, 2000; Ouhalla, 1994, 1997, 2005) due to their impact on the interpretation of the associate DP. In generative practice to grammar, expressiveness devices are widely taken as morphosyntactic output produced in the computational system of language that is sent over to the interface system for discourse-interpretive properties (Alshamari, 2017; Ouhalla, 1994, 1997). In a broader sense, clitic, for instance, is massively attested in most Romantic and Semitic languages, dialectal Arabic in this paper, and has been characterized a syntactic category that contributes to the interpretation of the 'functional or discoursal' host it is associated to or the argument 'DP' it doubles (Belletti, 1999; Uriagereka, 1995; Shlonsky, 2000; Ouhalla, 1994, 1997; Harizanov, 2014; Kramer, 2014; Shlonsky, 2000; Alshamari, 2017). In Arabic literature, the longstanding view on the interpretive properties of clitic concludes that it functions as an anchoring device in syntax linking a semantic entity expressed by a constituent (Ayoub, 1981; Bakir, 1980; Shlonsky, 2000; Aoun et al., 2010). For instance, Aoun et al. (2010) argue that clitic spelled out on a lexical verb, for instance, is an indication of movement of the DP to the left periphery, which is not in par with interface-motivated requirements as to how a clitic functions at the LF-interface system, which is not always plausible (Note 1). A plausible view in this respect is Ouhalla (1997), claiming that a clitic expresses old information, as in the Moroccan Arabic example (1) below from (Aoun et al., 2010, p. 48) (Note 2).

\section{(1) t-təffaha Somar kla-ha \\ Def-apple Omar eat.PST.3SG.M-3SG.F \\ 'The apple, Omar ate it.'}

Bringing Ouhalla's (1997) logic into practice, with the practice of the minimalist strategies of the generative research (Chomsky, 1995 et seq), along with the generative, minimalist mechanisms of agreement and movement (Chomsky, 2001), the syntax of clitic has been rethought, in dialectal Arabic, triggering inquiry as to 
how to legitimise it in an interface-oriented manner in a way that accounts for its co-occurrence with full pronouns (Alshamari, 2017).

Under this view, extending the topics typology advanced by (Frascarelli \& Hinterhölzl, 2007; Alshamari, 2017) provides empirical and conceptual evidence that a clitic is a product of the valuation of an occurrence of a set of unvalued $\varphi$-features, resulting in interpreting these $\varphi$-features at PF, spelling them out only when the DP has an instance of [Top] of some sort. Put differently, Alshamari (2017) shows that a clitic doubles DP while the DP is in situ, which could be taken as a PF-component that feeds into LF-interface that the doubled DP expresses Topic of some sort, building on Ouhalla $(1994,1997)$ proposal. A typical example of clitic in North Hail Arabic dialect is given below from Alshamari (2017, p. 93).

\section{(2) Pal-laGib lmisa-ah Pal-ku:rah \\ Def-player touched-3SG.F Def-ball}

'The player, the ball, he touched it.'

Alshamari (2017, p. 102) characterises the operation of spelling out the clitic $a h$ on the lexical verb as an output of an Agree relation held between the lexical verb and the object DP, what he formalises 'topical clitic generalisation'. Contra the received view proposed in the literature (cf., Shlonsky, 1997), Alshamari (2017) argues that spelling out clitic $a h$ on the verb, in Arabic in general terms, is due to the fact that the object DP has a feature [TOP] and that this feature is overtly spelled as a clitic, after an Agree relation has been held between $\mathrm{v}$ and the DP object in which the latter values the unvalued $\varphi$-features of the former. On the other hand, a pronoun, normally doubles a DP and is normally referential, as we will see. Amongst the properties a pronoun feature is related to information structure. That is, a pronoun characterises a topic or focus of the sentence (Jelinek, 2002). Against this background, the research will be an attempt to investigate data as the NHA example in (3) below, which raises, on conceptual grounds, inquiry as to what legitimises that amount of referentiality the pronominals carry at the LF-interface system (I forntbold expressiveness devices and other items like particles throughout the paper):
(3) Pinn-ah
Manal
hi xat $^{\mathrm{s}}$-at
Pal-fustan
bi-l-s salah $^{-1}$
Confirmation-3SG.
Manal
she sew.PST-3SG.F Def-dress
in-Def-lounge

Roughly translated: 'That she, Manal, she sewed the dress in the lounge.'

The clause in (3) contains two instances of expressiveness devices, both of which agree in $\varphi$-features with the subject DP Manal, which they mark or double, using Uriagereka's (1995) terminology: the clitic $a h$ spelled out on the complementizer Pinn and the pronominal hi. This being raised, the rest of the paper will be dedicated to propose a plausible generative, minimalist, interface analysis to the syntax and morphosyntax of the expressiveness devices therein, accounting for their merge and legitimacy at the interface system with respect to their syntactic positions in the clause.

The paper is structured as follows. Section two touches on the descriptive nature of the data to be explored, highlighting certain phenomena where expressiveness devices' effects can be noticed. This also incorporates, where relevant, some hypotheses and generalisations proposed in the related literature. Section three is dedicated to a generative, minimalist analysis of the phenomenon, including the implementation of the generative model of Chomsky's theory of agreement and the related assumptions. This will deal with the motivation of movement when it occurs, attributing it to feature valuation and visibility to a valuator up in the structure. In addition, this section involves principles, conditions and constrains relevant to the practice of the Agree and movement mechanisms with respect to the phase theory (Chomsky, 2001) and the cartographic approach (Rizzi, 1997, 2004). Section four highlights some generalisations raised by the outcomes of the research and provides suggestions further proposals and line of research. Section Five concludes the research.

\section{Data and the Syntactic Phenomenon}

One of the issues widely investigated is the motivation of spelling expressiveness devices in syntax, especially where they co-occur with and double DPs (Uriagereka, 1995). In this case, clitic, for instance, as one of the intensively investigated form of expressiveness devices, has been characterized in one of two ways. Clitic is an item that incorporates onto a head or an agreement that spells out agreement features of the doubled DP on an expressiveness device, lexical, functional or discoursal head (cf., Ouhalla, 1994, 1997; Ouhalla \& Shlonsky, 2002; Aoun et al., 2010). This linguistic process is analysed by means of movement of the clitic from within a DP, following Uriagereka (1995) and Bakir (1980). Current development in generative practice to grammar has abstracted away from incorporation approach and reconsidered clitic as a linguistic category featuring its own 
syntactic and discourse properties, having interface motivations (Holmberg \& Hróarsdóttir, 2003; Alshamari 2017). On theoretical and practical grounds, clitic is a syntactic object that spells out the $\varphi$-features of a DP during the course of the derivation of a sentence because the topicalised DP carries discourse information. In this way, a clitic is in par with economy considerations and interface requirements (Chomsky, 2001) in that it occurs only when the sentence is discourse-linked.

Consider the NHA example in (3) above, repeated below as (4):

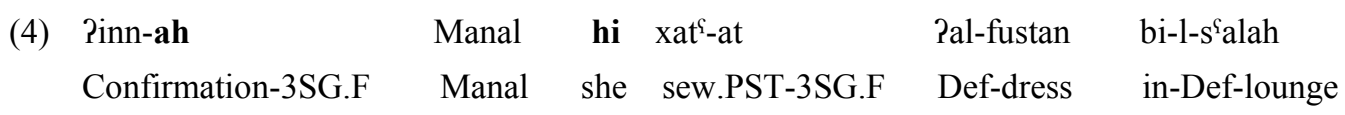

Roughly translated: 'That she, Manal, she sewed the dress in the lounge.'

A first glance, we can see that the clitic ah spelled out on the complementizer Pinn and the pronoun hi, all contribute to the discourse interpretation of the propositional content of the clause, indicating that we deal with an extra-linguistic level of language. In $(3,4)$, then, we have three referential items $a h$, spelled out on Pinn and the pronoun $h i$, both of which are co-indexed and associated with the subject DP Manal.

With further investigation to the structure in $(3,4)$, is that there seems to be constraints held on its syntax. Consider (5):

(5) Pinn-ah

HI Manal xat'-at

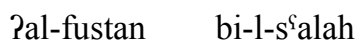

Confirmation-3SG.F she Manal sew.PST-3SG.F Def-dress in-Def-lounge

Roughly translated as: 'That she, Manal, SHE (not some other girl) sewed the dress in the lounge.'

It can be deduced from (5) that the expressiveness devices each is licenced in a certain position in syntax, where it is licit at the interfaces. Furthermore, endowed with phonological or morphosyntactic import, these items seem to be conditioned at the pragmatic-phono-syntactic interface system. For instance, the pronoun is allowed to co-occur with the subject DP, merged to the right of it as in $(3,4)$. However, it is only allowed to the left of the subject DP when it is contrastively stressed as in (5).

Another fact demonstrated by these data is that merging more agreeing articulated structure in the clause seems to show more about the nature of the interface conditions and constraints imposed on the syntax of NHA. This can be captured when an agreeing demonstrative is added into the numeration of the clause in (5), as shown in (6).

$\begin{array}{lllllll}\text { Pinn-ah } & \text { haði } & \text { Manal } & \text { HI } & \text { xat }^{\mathrm{\varsigma}} \text {-at } & \text { Pal-fustan } & \text { bi-1-s'alah } \\ \text { Confirmation-3SG.F } & \text { Dem.3SG.M } & \text { Manal } & \text { she } & \text { sew.PST-3SG.F } & \text { Def-dress } & \text { in-Def-lounge }\end{array}$

Roughly translated as: 'Manal, this girl, she sewed the dress in the lounge.'

The demonstrative haði agrees in $\varphi$-features with the subject DP Manal, turning the left periphery of the clause rich at PF with spelling out expressive notions, spelling $\varphi$-features information and rich at LF interface, containing several discourse-related notions. The next section discusses the syntactic observations evidenced in (6), exploring the syntactic positions the expressiveness devices have in syntax, highlighting on the constraints held on their positioning in narrow syntax and their full interpretation at the interfaces.

\section{Exploring the Data and Analysing the Linguistic Properties}

Given the fact that the lexical verb moves to T, as the received view in Arabic in general terms (Ouhalla, 1994), in all examples above it follows that the preverbal thematic subject DP Manal moves to Spec of TP when surfing preverbally. Follows directly from this is fact the preverbal subject is in the CP domain, which can be captured by the observation that the contrastively stressed pronoun $H I$ intervenes between the preverbal subject DP and the lexical verb (Note 3). Given that the demonstrative haði precedes the subject DP Manal, hað i is indeed in CP. Notice in passing, interestingly, that both the clitic ah on Pinn and the demonstrative haði agree in $\varphi$-features with the subject DP Manal. Notice also that any other order, containing these agreeing syntactic items, is disallowed in NHA grammar. The next sub-section touches on the main arguments triggered by the syntax of (6), including what seems to be an instance of multiple agreement.

\subsection{Mechanisms of Agreement}

Let us first consider the observation that two items c-commanding the subject DP Manal overtly agree with it in $\varphi$-features and how the mechanisms of the current theory can account for this. Firstly, it is not huge leap to assume that the subject DP is in the left periphery, given that it is immediately followed by a contrastively stressed pronoun $H I$. Being contrastively stressed, one would immediately stipulate that $H I$ expresses new, 
non-discourse given information, hence, Focus in the sense of Rizzi (1997). However, this stipulation is directly ruled out on the basis that the expressiveness device $H I$ is used to select the entity expressed by the subject DP out of a discourse given set of entities from within the common ground (Stalnaker, 2002), an argument I base against the observation that this DP and the associated pronoun are retrieved via the clitic on the complementizer Pinn, which is a topical item (Ouhalla, 1994, 1997; Krifka, 2007). Under this view, I propose that HI in (7) represents contrastive topic in the sense of Frascarelli and Hinterhölzl (2007). This being the case, (6) is schematised in (7) below:

(7)

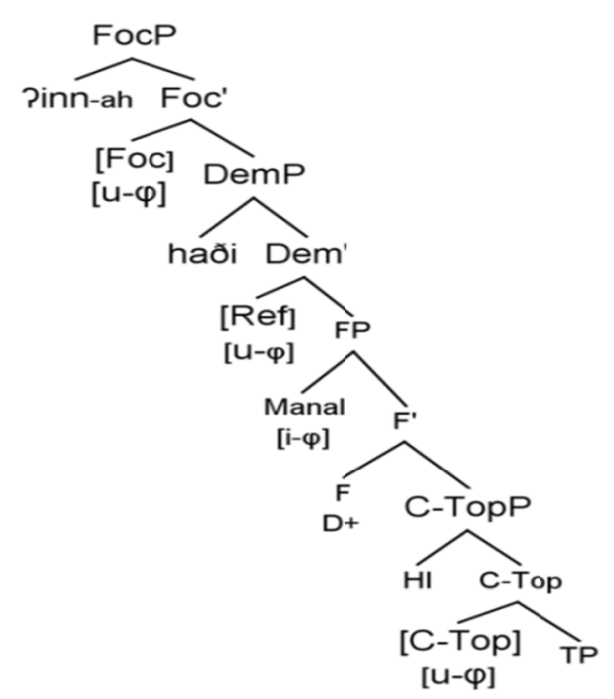

I therefore assume that contrastive stressed items are licensed in syntax in positions where they contribute to the interpretation of the clause at the LF interface, i.e., Contrastive Topic phrase. What the schemata in (7) shows is that the three instances of information interacting with the subject DP Manal. The information present on $\mathrm{Foc}^{\circ}$ is new information with a colour of confirmation in the sense of Ouhalla $(1994,1997)$. This process results in an agreement between the head $\mathrm{Foc}^{\circ}$ hosting the Foc information and the subject DP Manal, with the consequence that the clitic ah, used as an expressiveness device spelled out at the PF interface and thereby marking the DP. The demonstrative haði also displays the grammatical information third person singular feminine expressed on it, which indicates that Dem ${ }^{\circ}$ has been in an Agree relation (Chomsky, 2001) with the subject DP at a certain point of the derivation, hence, the subject DP is also marked with referentiality. Finally, the contrastively stressed pronoun $H I$ spells the $\varphi$-features of the subject DP, with an additional PF component, the contrastive stress, which renders the subject DP interpreted as contrasted at the LF (Note 4). These phenomena will be explained in the next subsection. In this subsection, I show a formal analysis to the phenomena presented in (7), formulating a proposal about the nature of features, agreement processes and the syntax of (7), and using mechanisms of Agree in current minimalist approach to grammar (Chomsky, 2001).

\subsection{Agree Between the Expressiveness Devices and the Subject DP}

Let us first explore how agreement is processed between the two seemingly probes and the single goal, the subject DP Manal, using Chomsky's (2001) strategies of features and feature valuation. On the basis that agreement is overtly spelled out on Pinn and on the demonstrative haði, it can feasibly be assumed that they both have an occurrence of $\varphi$-features, which I argue are uninterpretable/unvalued (Chomsky, 2001) because $\varphi$-features don't contribute to the interpretation of a clause on functional items within functional positions. In minimalist practice and with respect to interface requirements, these unvalued features need to be valued and deleted before the derivation reaches the interpretive systems (Chomsky, 1995).

Having outlined facts about agreement within (6), we are now ready to return to the issue of how agreement is processed in syntax.

As hinted above, I propose that Pinn is the PF component of Focus information. Spelling out the clitic on Pinn indicates that Pinn has established an Agree relation with the subject DP, Pinn $\varphi$-probes the subject DP. The same logic holds true for $h a ð i$ and the subject DP, the former $\varphi$-probes the latter, as schematised in (8): 
(8)

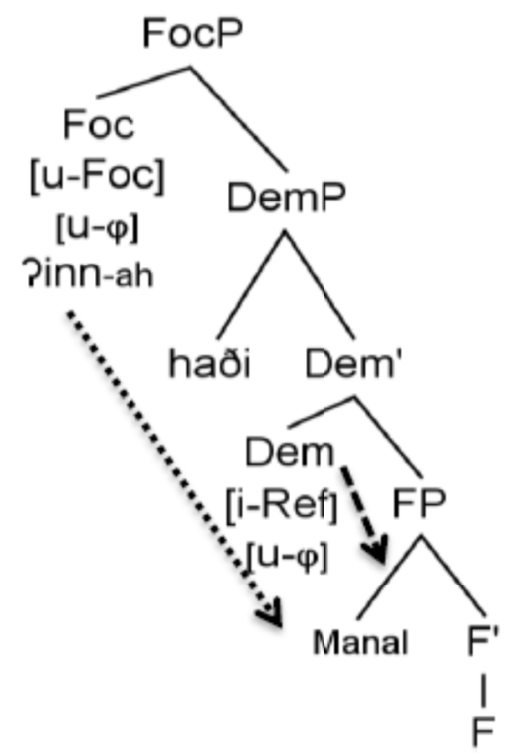

The head Dem ${ }^{\circ}$ has an instance of valued [Ref] (Note 5) and unvalued $\varphi$-features. Once merged, Dem ${ }^{\circ} \varphi$-probes the subject DP, being local in its c-command domain. Agree then occurs due to the effects of a crucial principle of grammar, the Minimal Link Condition (MLC) (Chomsky, 1995, pp. 355-356).

(9) Minimal Link Condition

A feature $\mathrm{F}$ attracts the closest feature that can check $\mathrm{F}$.

According to MLC, (9), unvalued [ $\varphi$ ] on Dem ${ }^{\circ}$ enters into an Agree relation with the subject DP. The subject DP, endowed with valued $\varphi$-features, values the unvalued $\varphi$-features on Dem ${ }^{\circ}$. The output of this Agree relation is spelling out haði at the PF interface, while the consequence at the LF interface is the subject DP being interpreted as referential. The other instance of Agree is the novel here. Notice that, derivationally, once hadi has accomplished Agree with the subject DP, we predict Pinn to merge into the derivation, the point at which it $\varphi$-probes the subject DP (Note 6). As (8) shows, ?inn probes through hadi, a procezss which suggests that Dem ${ }^{\circ}$ doesn't cause intervention effects to Foc $^{\circ}$ probing (Rizzi, 1997, 2004).

With this generalisation formulated, in the following subsection, I take up the discussion on the agreement and syntax of the structure below the subject DP.

\subsection{Agree of Expressiveness Devices Below the Subject DP}

I take the subject DP to have entered Agree relation in situ, at the Spec position of TP, resulting in interpreting the subject DP as C-Topic at the LF. This takes place by getting the subject DP linked up in a chain whose head is the $H I$ pronoun at the PF interface, the output of this Agree, following the line of analysis proposed in Alshamari (2017). This is represented in (10) (downwards arrow represents Probing while upward dotted arrow represents PF-chain): 
(10)

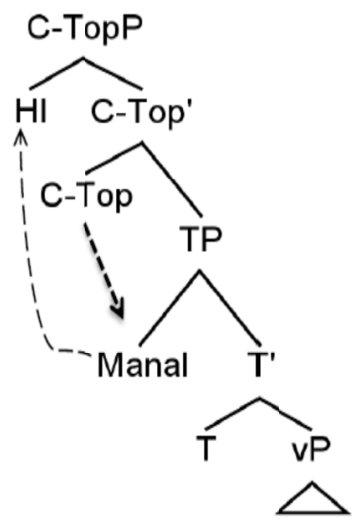

Afterwards, the subject DP moves from its thematic position to the Spec position of a functional projection, licensed for discourse interpretation. In a derivational manner, this movement would have taken place before $h a ð i$ and Pinn had merged in the derivation but after the contrastively stressed item $H I$ was merged. This can be represented below in (11):

(11)

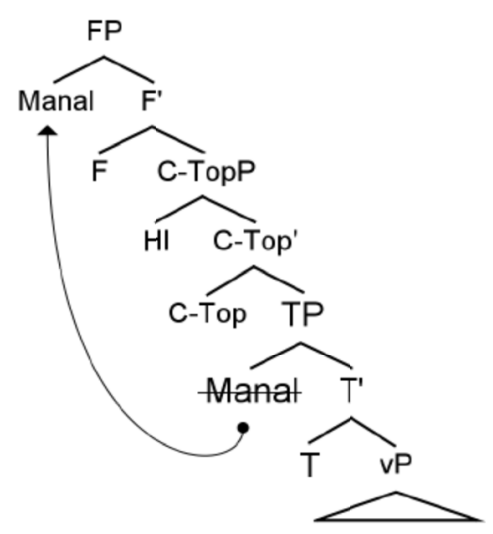

In theory, and given the scenario above that Pinn probes through haði, one would expect that Pinn and haði, as a complex probe, would probe the subject through the null C-Top, which otherwise would have given the ill-formed sentence in (12):

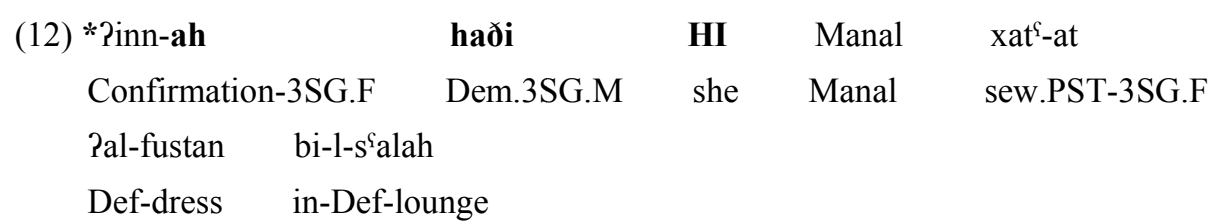

Intended meaning: 'Manal, this girl, she sewed the dress in the lounge.'

The chain thereby created by $H I$ and Manal in situ is interpreted C-Topic at the interfaces and the subject DP is satisfied at this point of the derivation. Movement of the subject DP across C-ToP, then, follows from the fact that there is a feature on it (Bošković, 2007) or on a functional head up in the structure (Lasnik, 1995), a matter I explain in the follow subsection.

3.4 Movement of Subject DP to FP Across C-TopP

Consider the point of the derivation at which the subject DP lands at the Spec position of FP, as in (13) below: 
(13)

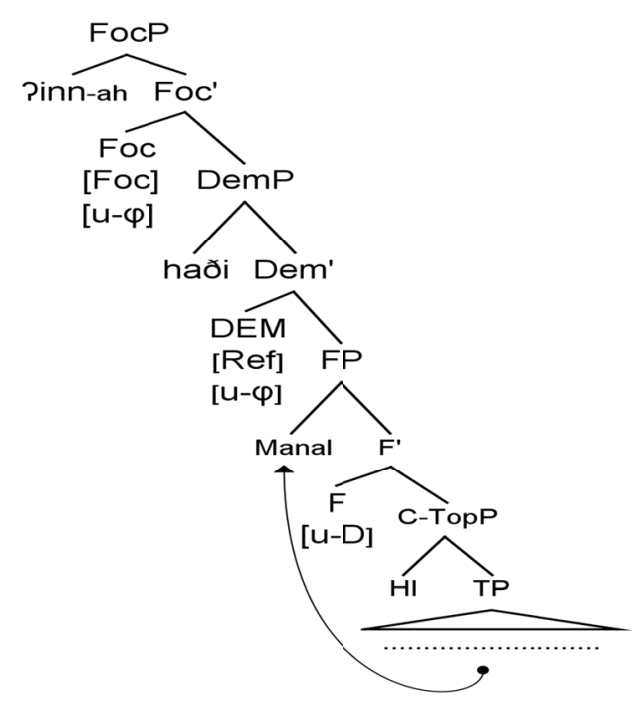

Given the argument above, that $\mathrm{Foc}^{\circ}$ and $\mathrm{Dem}^{\circ}$ probe the subject DP (in which case $\mathrm{Foc}^{\circ}$ probes through $\mathrm{Dem}^{\circ}$ ), there would be no reason to ban on the two probe heads, $\mathrm{Foc}^{\circ}$ and $\mathrm{Dem}^{\circ}$, to probe the subject DP. This is directly associated with the problematic phenomenon that the subject moves after it has been assigned the C-Top interpretation. These issues need to be accounted for with respect to interface requirements. Bošković's (2007) account that movement is always triggered by an unvalued feature that moves to escape its own phase Transfer (Chomsky, 2001) can be plausibly adopted if we assume that there is an unvalued feature on the subject DP.

But we also have a problem here, where the subject moves even it is predicted to have been probed by C-Top ${ }^{\circ}$ plus the fact that it has a set of $\varphi$-features which are already valued. With all these facts at hand, I assume that the subject DP is actually attracted by the c-commanding probes $\mathrm{Foc}^{\circ}$ and $\mathrm{Dem}^{\circ}$ in an altruism fashion, in the sense of Lasnik (1995). It follows from this assumption that there is some syntactic constraint in the NHA grammar, blocking the probing heads $\mathrm{Foc}^{\circ}$ and $\mathrm{Dem}^{\circ}$ from accessing the subject DP. I formally state this constraint along the following lines:

(14) NHA constraint on multiple probing heads

Being in the left periphery, stacked, only two probing heads $\alpha$ and $\beta$ can probe a single goal, provided that no third probing head $\gamma$ exists intervenes between the two probing heads and the single goal.

With (14) at hand, (15) below is a problem.

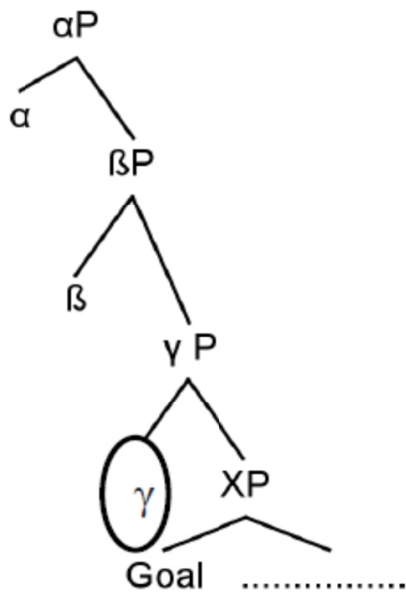

Interface system, which is an interpretive system rather than a structuring system, seems to impose constraints on syntax, including. That is, such constraints and conditions might well be in par with chains formation and maintenance of the chains in syntax and at the interface system. That is, expressiveness devices instantiates syntactic positions for certain interpretive properties which contribute to the full interpretation of the clause (or parts of the clause, items). However, the mechanisms by which they interact with the DP are constrained and 
conditioned by the interface system, both sound and thought. Agreement is available in syntax, reducing movement as much as possible and allowing for it only when syntax requires so, for reasons related to the optimal structure of the faculty of language.

\section{Generative Generalisations}

A few assumptions can further be gleaned from the syntax of the structure investigated in this paper and be extended to natural language. One is the fact that movement operations, applied in syntax for interpretive properties and discourse values, are conditioned by the interface systems. Movement is not free in a sense that it is activated when an agreement relation is present, resulting in a spec head configuration to agreement. Thus, an item can serve as a proper goal and be probed if it is properly visible to the probing item. In the same vein, it must move if it needs to get a value to an unvalued feature on it or if there is a need to value one up in the structure. This property of syntax immediately supports the assumption that movement presupposes agreement (Chomsky, 2001). What this research also raises is the fact that computation is quite flexible when it comes to agreement by probe-goal relation in that it allows a probing head to practice probing a goal through another, c-commanded, probe, hence, optimality of natural language.

\section{Conclusion}

This research has offered an investigation to a linguistic phenomenon, where multiple occurrences of expressiveness devices, clitic, pronoun and demonstrative, co-occur, mark and agree with a DP. Exploring a set of data from NHA, it was shown that each instance of expressiveness devices instantiates its own syntactic projection, phrasal or head, and each involves certain information related to discourse. In syntax, it is generalised that multiple probing takes places, in which case two probes probe a single goal. It was also shown that in this case, while the upper probe probes through the lower probe, visibility is not problematic in the higher goal is visible to the higher prob. Deduced for the analyses held is the fact that grammar of NHA allows syntax to have instances of multiple agreement but imposes constrains and conditions for that. For instance, only two probing heads can be adjacent. In case there is a further probing head in the c-commanding domain of the two adjacent probing heads, the goal is not visible and movement of the goal is triggered. This might suggest that in the CP domain, there is a constraint managing the number of goals with respect to visibility. output of research has advanced the assumption that $\mathrm{CP}$ in NHA is rich with articulates discourse spines.

\section{References}

Alshamari, M. R. (2017). Topic particles in the North Hail dialect of Najdi Arabic. Doctoral dissertation: Newcastle University. Retrieved from https://theses.ncl.ac.uk/jspui/handle/10443/3915

Aoun, J., Benmamoun, E., \& Choueiri, L. (2010). The syntax of Arabic. Cambridge: Cambridge University Press. https://doi.org/10.1017/CBO9780511691775

Ayoub, G. (1981). Structure de la Phrase en Arabe Standard. Doctoral dissertation: Universit'e de Paris VII, France.

Bakir, M (1980). Aspects of clause structure in Arabic. Doctoral dissertation: Indiana University, Bloomington.

Belletti, A. (2004). Aspects of the low IP area. In L. Rizzi (Ed.), The structure of CP and IP (pp. 16-51). Oxford: Oxford University Press.

Bošković, $\breve{Z}$ (2007). On the locality and motivation of Move and Agree: An even more minimal theory. Linguistic Inquiry, 38, 589-644. https://doi.org/10.1162/ling.2007.38.4.589

Chomsky, N. (1995). The minimalist program. Cambridge: MIT Press.

Chomsky, N. (2001). Derivation by phase. In M. Kenstowicz (Ed.), Ken Hale. A Life in Language (pp. 1-52). Cambridge: MIT Press.

Frascarelli, M., \& Hinterhölzl, R. (2007). Types of Topics in German and Italian. In S. Winkler \& K. Schwabe (Eds.), On Information Structure, Meaning and Form (pp. 87-116). Amsterdam: John Benjamins. https://doi.org/10.1075/la.100.07fra

Harizanov, B. (2014). Clitic doubling at the syntax-morphophonology interface. Natural Language \& Linguistic Theory, 32(4), 1033-1088. https://doi.org/10.1007/s11049-014-9249-5

Hiraiwa, K. (2001). Multiple agree and the defective intervention constraint in Japanese. MIT Working Papers in Linguistics, 40(40), 67-80.

Holmberg, A., \& Hróarsdóttir, T. (2003). Agreement and movement in Icelandic raising constructions. Lingua, 113(10), 997-1019. https://doi.org/10.1016/S0024-3841(02)00162-6 
Jelinek, E. (2002). Agreement, clitics and focus in Egyptian Arabic. In J. Ouhalla \& U. Shlonsky (Eds.), Themes in Arabic and Hebrew syntax (pp. 71-105). Springer, Dordrecht. https://doi.org/10.1007/978-94-010-0351-3_3

Kramer, R. (2014). Clitic doubling or object agreement: The view from Amharic. Natural Language \& Linguistic Theory, 32(2), 593-634. https://doi.org/10.1007/s11049-014-9233-0

Krifka, M. (2007). Basic Notions of Information Structure. In C. Fery, G. Fanselow \& M. Krifka (Eds.), The Notions of Information Structure, Interdisciplinary Studies on Information Structure (vol. 6, pp. 13-55). https://doi.org/10.1556/ALing.55.2008.3-4.2

Lasnik, H. (1995). Case and expletives revisited: On Greed and other human failings. Linguistic Inquiry, 26, 615-633.

Ouhalla, J. (1994). Focus in standard Arabic. Linguistics in Potsdam, 1, 65-92.

Ouhalla, J. (1997). Remarks on focus in Standard Arabic. In M. Eid \& R. R. Ratcliffe (Eds.), Perspectives on Arabic linguistics X: papers from the Tenth Annual Symposium on Arabic Linguistics (pp. 9-45). Amsterdam: John Benjamins. https://doi.org/10.1075/cilt.153.04ouh

Ouhalla, J. (2005). Clitic placement, grammaticalization, and reanalysis in Berber. In The Oxford handbook of comparative syntax.

Rizzi, L. (1997). The fine structure of the left periphery. In L. Haegeman (Ed.), Elements of Grammar (pp. 281-337). Dordrecht: Kluwer Academic Publishers. https://doi.org/10.1007/978-94-011-5420-8_7

Rizzi, L. (2004). Locality and the left periphery. In A. Belletti (Ed.), Structure and Beyond (pp. 223-251). Oxford: Oxford University Press.

Shlonsky, U. (1997). Clause structure and word order in Hebrew and Arabic: An essay in comparative Semitic syntax (pp. 9-45). Oxford: Oxford University Press.

Shlonsky, U. (2000). Remarks on the Complementizer layer of Standard Arabic. In J. Lecarme, J. Lowenstamm \& U. Shlonsky (Eds.), Research in Afroasiatic Grammar: Papers from the Third conference on Afroasiatic Languages, Sophia Antipolis, 1996 (pp. 325-343). Amsterdam/Philadelphia: John Benjamins Publishing. https://doi.org/10.1075/cilt.202.15shl

Uriagereka, J. (1995). Aspects of the syntax of clitic placement in Western Romance. Linguistic Inquiry, 26(1), $79-123$.

\section{Notes}

Note 1. See Alshamari (2017) for argument against this proposal.

Note 2. Interlinear glossing is modified by the author of this research in accordance with Leipzig Glossing Rules.

Note 3. I will obey the theory that the lexical verb moves from $\mathrm{v}$ to $\mathrm{T}$ in syntax, until otherwise some evidence arises supporting other postulations.

Note 4. The subject DP is interpreted as contrasted at LF only, but in connection with the contrastively stressed pronoun $H E$, which has the PF-component contrastive stress, both of which are involved in a chain.

Note 5. Ref notates Referentiality.

Note 6 . The subject is still in the vicinity of the higher probe, Pinn. In theory, ?inn is predicted to probe the subject DP, following Hiraiwa (2001).

\section{Copyrights}

Copyright for this article is retained by the author, with first publication rights granted to the journal.

This is an open-access article distributed under the terms and conditions of the Creative Commons Attribution license (http://creativecommons.org/licenses/by/4.0/). 